\title{
Blue-shifted and picosecond amplified UV emission from aqueous chemical grown $\mathrm{ZnO}$ microrods
}

Melvin John F. Empizo ${ }^{\mathrm{a},{ }^{*}}$,Kohei Yamanoi ${ }^{\mathrm{a}}$, Alexandra B. Santos-Putungan ${ }^{\mathrm{b}, \mathrm{c}}$, Ren Arita ${ }^{\mathrm{a}}$, Yuki Minami $^{a}$, Mui Viet Luonga ${ }^{\mathrm{a}}$, Toshihiko Shimizu ${ }^{\mathrm{a}}$, Elmer S. Estacio ${ }^{\mathrm{c}}$, Armando S. Somintac ${ }^{\mathrm{c}}$, Arnel A. Salvador ${ }^{\mathrm{c}}$, Roland V. Sarmago ${ }^{\mathrm{c}}$, and Nobuhiko Sarukura ${ }^{\mathrm{a}}$

${ }^{a}$ Institute of Laser Engineering, Osaka University, 2-6 Yamadaoka, Suita, Osaka 565-0871, Japan

${ }^{b}$ Institute of Mathematical Sciences and Physics, University of the Philippines Los Baños, College, Laguna 4031, Philippines

${ }^{c}$ National Institute of Physics, University of the Philippines Diliman, Diliman, Quezon City 1101, Philippines

*Corresponding author: mjfempizo@ile.osaka-u.ac.jp

\begin{abstract}
Room-temperature amplified spontaneous emission (ASE) has been observed from aqueous chemical grown zinc oxide $(\mathrm{ZnO})$ microrods. The well-faceted microrods have only a single narrow ultraviolet (UV) emission at $390 \mathrm{~nm}(3.2 \mathrm{eV})$ with average lifetimes as fast as 85 to 100 ps. The characteristic ASE also exhibits blue-shifted peaks and shortened lifetimes. At present, the peak shifting and the lifetime shortening are attributed to the band filling and photo-induced screening effects and to the nonradiative relaxation process, respectively. Results indicate that the $\mathrm{ZnO}$ microrods have good structural and optical quality which leads to their suitable use for optoelectronic applications.
\end{abstract}

Keywords: ZnO, II-VI semiconductor, microrods, solution growth, photoluminescence 


\section{Introduction}

Zinc oxide $(\mathrm{ZnO})$ has attracted much attention as a candidate material for various ultraviolet (UV) devices such as detectors, light emitting diodes (LEDs), laser diodes, among others[1].Its wide and direct band gap $(3.3 \mathrm{eV})$ and large exciton binding energy $(60 \mathrm{meV})$

5 enable efficient excitonic UV emission at room and even higher temperatures [2].With the increasing variety of $\mathrm{ZnO}$ growth methods being implemented, high quality single crystals and a massive assortment ofmicro/nanostructures have already been produced.Among the techniques used, the aqueous chemical growth (ACG) method (often referred to as hydrothermal method orsolution route)is a low cost, simple, and effectivewayto

10 fabricatehexagonaland crystalline $\mathrm{ZnO}$ micro/nanostructures.Using tabletop equipment and few chemicalprecursors, $\mathrm{ZnO}$ rods [3-9], flowers or multipods [10-12], stars [13], prisms [14], and nanoparticles [15]are produced with high yield at relatively low temperatures. $\mathrm{ZnO}$ microrods prepared by ACG, for example, can be isolated and can be used for device fabrication [16]. With the advancement of optical characterization techniques, stimulated

15 emission and lasing action from different $\mathrm{ZnO}$ materialshave also been observed [17-24].Investigatingthe phenomena governing dynamic optical transitions is important for the fundamental understanding and full integration of these $\mathrm{ZnO}$ materials into their potential applications.

In this work, we report the amplified stimulated emission (ASE) of uniform and well-faceted $\mathrm{ZnO}$ microrods fabricated by the ACG method. The ASE is evidenced by the increase in the emission intensity and the decrease of the spectral linewidth with increasing optical excitation energy density. The microrods also exhibit blue-shifted peaks and shortened picosecond lifetimes attributed to the band filling and screening effects and to the nonradiative process, respectively. These observations give helpful insights on the use of the microstructures for their potential UV optoelectronic applications. 


\section{Experimental}

Aqueous chemical growth methodwas implemented in fabricating $\mathrm{ZnO}$ microrods. Equimolar concentrations of zinc acetate dihydrate $\left(\mathrm{Zn}\left(\mathrm{CH}_{3} \mathrm{COO}\right)_{2} \cdot 2 \mathrm{H}_{2} \mathrm{O}\right)$ and hexamethylenetetramine $\left(\left(\mathrm{CH}_{6}\right)_{2} \mathrm{~N}_{4}\right)$ aqueous solutions were homogenously mixed in a beaker through ultrasonication. A (100) silicon (Si) substrate was then submerged into the solution and was set at the bottom of the beaker. The solution was eventually heated at $95{ }^{\circ} \mathrm{C}$ for $120 \mathrm{~min}$ in ambient atmosphere. After heating, the substrate was removed from the solution and was air-dried. The air-dried sample was subsequently annealed at $370{ }^{\circ} \mathrm{C}$ for 60 min in ambient air. A typical morphology of the as-prepared $\mathrm{ZnO}$ sample is shown in Fig. $\mathbf{1 .}$ Hexagonal structures are observed lying horizontally on the substrate exposing their prism sides to the surface. The well-faceted rods are homogenous with uniform lengths and widths ranging from 6 to $20 \mu \mathrm{m}$ and 0.4 to $1.3 \mu \mathrm{m}$, respectively. A $10 \mu \mathrm{m}$ x $10 \mu \mathrm{m}$ area of the sample is occupied byapproximately 11 microrods.X-ray diffraction (XRD) spectroscopy results also

40 reveal that the as-prepared samples have reflections corresponding to hexagonal wurtzite $\mathrm{ZnO}$.

Time-resolved photoluminescence (TRPL) spectroscopy was performed at room temperature to investigate the optical emission of the as-prepared $\mathrm{ZnO}$ microrods. The frequency tripled output $(3 \omega, 290 \mathrm{~nm})$ of a Ti:sapphire laser system with $1 \mathrm{kHz}$ repetition rate and 100 fs pulse duration was used as the excitation source. The laser beam having a spot size ranging from 220 to $450 \mu \mathrm{m}$ was made incident at an angle of $45^{\circ}$ from the surface normal to the sample. Varying laser pump powers wereused and were measured using a calibrated power meter. The sample emission was then collected also normal to the sample by a fiber optic bundle and was directed to an imaging spectrographfitted with 600 grooves/mm grating.

50 The spectrograph was coupled to a streak camera in conjunction with a UV-Vis high 
resolution charged-couple device (CCD) camera. The spectrograph-camera system has a spectral resolution of $1 \mathrm{~nm}$ and a temporal resolution of $10 \mathrm{ps}$.

\section{Results and discussions}

The initial room-temperature wide scan PL spectrum of the $\mathrm{ZnO}$ microrods prepared by the ACG method is shown in Fig. 2. Only one narrow emission peak is observed at 390 $\mathrm{nm}(3.2 \mathrm{eV})$ corresponding to the near-band-edge emission of $\mathrm{ZnO}$ [25]. Compared with the usual $\mathrm{ZnO}$ near-band-edge emission peaks at $\sim 380 \mathrm{~nm}$, the sample emission is slightly shifted to longer wavelengths (lower energies). The shift may be due to the relative contributions of the excitonic recombination and its longitudinal optical (LO) phonon replicas and/or to the thermal effects caused by laser heating [26-28].In contrast with $\mathrm{ZnO}$ micro/nanostructures similarly fabricated by ACG method [4-11, 14, 15] and to those prepared by different techniques [29-31], the microrods do not exhibit any visible defect-related emissions. This result implies that the as-prepared $\mathrm{ZnO}$ microrod samples are

65 of good optical quality.

Streak camera images of the room temperature UV emissions of the aqueous chemical grown $\mathrm{ZnO}$ microrods at different excitation energy densities are shown in Fig. 3. All streak camera images are normalized for easier comparison. The corresponding integrated spectral and temporal profiles are also presented in Figs. 4 (a) and (b), respectively. At an excitation of $100 \mu \mathrm{J} / \mathrm{cm}^{2}$, the emission is faint and very weak. The emission becomes very intense and narrow at higher excitation up to $410 \mu \mathrm{J} / \mathrm{cm}^{2}$. Investigating the emission intensities and spectral linewidths (full-width at half maximum or FWHM), the light-light (L-L) curve of the $\mathrm{ZnO}$ microrods is shown in Fig. 5. With increasing optical excitation, the integrated emission intensity increases while the linewidth decreases. This energydependence

75 of the room temperature $\mathrm{UV}$ emission of the $\mathrm{ZnO}$ microrods, specifically the linear increase 
of intensity with incident pump energy, indicates an amplified spontaneous emission (ASE).

The room temperature UV emission peaks and average lifetimes of the $\mathrm{ZnO}$ microrods fabricated by the ACG method are also examined. The emission peak centers of the $\mathrm{ZnO}$ microrods at different excitation energy densities are plotted in Fig. 6(a). The peaks shift to shorter wavelengths by 1 to $3 \mathrm{~nm}$ (i.e. higher photon energies) with increasing energy density. Similar observationisalso reportedfor various $\mathrm{ZnO}$ nanowire samples[22, 32, 33].Meanwhile, the average lifetimes of the UV emissions of the $\mathrm{ZnO}$ microrods at different excitation energy densities are shown in Fig. 6(b). From the decaying part of the temporal profiles like those depicted in Fig. 4 (b), the lifetimes are determined by fitting a biexponential function of the form:

$$
I(t)=A_{1} \exp \left(\frac{-t}{\tau_{1}}\right)+A_{2} \exp \left(\frac{-t}{\tau_{2}}\right)
$$

where $I$ is the emission intensity, $t$ is time, $A_{1}$ and $A_{2}$ are the numerical coefficients, and $\tau_{1}$ and $\tau_{2}$ are the computed decay constants. From thefitted biexponential functions, the average lifetimes, $\bar{\tau}$ are then calculated using the formula [34]:

$$
\bar{\tau}=\frac{A_{1} \tau_{1}^{2}+A_{2} \tau_{2}^{2}}{A_{1} \tau_{1}+A_{2} \tau_{2}}
$$

The $\mathrm{ZnO}$ microrods have fast average UV emission lifetimes around85 to $100 \mathrm{ps}$. TheUV emission lifetimes also shorten with increasing energy density.

The aqueous chemical grown $\mathrm{ZnO}$ microrods exhibit room-temperature amplified spontaneous UV emission without any fabricated mirrors, sample cleavage, or sample 95 etching.This observation is also similar to other $\mathrm{ZnO}$ materials in the form ofstar-shaped structures [13],micro/nanowires[35-37], nanofibers [38], ridges [39], particles [40], photonic crystals [41], and even heterojunctions [42].Amplified spontaneous emission is an optical process usually satisfied in the high density optical excitation wherein the spontaneously emitted photons are amplified $[\mathbf{3 5}, \mathbf{4 3}]$.This phenomenon is observed from the microrods because of their inherent structural and optical properties. The $\mathrm{ZnO}$ microrods exhibit uniform 
dimensions andhexagonal cross sections (Fig. 7(a)). This structural property of the microrods is related to the hexagonal wurtzite crystal structure of $\mathrm{ZnO}$. The $\mathrm{ZnO}$ crystal structure (Fig. 7 (b)) is made up oftetrahedrally coordinated zinc $\left(\mathrm{Zn}^{2+}\right)$ and oxygen $\left(\mathrm{O}^{2-}\right)$ ions stacked alternately along the $c$-axis. The $\mathrm{Zn}$-terminated and $\mathrm{O}$-terminated sides produce a net 105 positively-charged and negatively-charged surfaces, respectively [11]. With thedissociative nature of the ACG method and the polarity of the $\mathrm{ZnO}$ crystal structure, the $\mathrm{ZnO}$ microrodswould then follow a typical hexagonal crystal habit (Fig. 7 (c)) $[\mathbf{4 4 , 4 5}$. Since the (0001) plane has the fastest growth rate, the microrods would have a preferred $<0001>$ growth direction(along its length) while being bounded by the (1010) faces (its

110 prism sides $)[\mathbf{8}, \mathbf{1 1}, \mathbf{4 5}, \mathbf{4 6}]$.As a material, $\mathrm{ZnO}$ has a refractive index (2.1 to 2.45) larger than air (1.00) and smaller than Si (3.45) $[35,38,39,47,48]$. The microrods' homogenous and well-faceted surfaces then form a good structure providing optical confinement and efficiently reducing UV transmission losses at the sides $[35,39]$. These hexagonal surfaces serve as parallel mirrors causing multiple internal reflections of the microrods' emission 115 inside the microstructure (Fig. 7(d)).Since the microrods do not exhibit any defect-related emissions, only the UV emission is being stronglyconfined leading to its amplified emission.

Moreover, the ASE of the $\mathrm{ZnO}$ microrodsis characterized by blue-shifted peaks and shortened lifetimes.At present, we offer band filling and photo-induced screening effects and nonradiative relaxation process as explanations for these observations. The blue-shift of the emission is attributed to the band-filling and/or photo-induced screening effects. Intensifying the incident laser pump energy induces an increase in the kinetic energy and density of excitons.As J.C. Johnson et al. pointed out, when "the exciton density increases, the binding energy decreases as the excitons are screened because of the strong Coulombic interactions with free carriers"[22].The screening itself causes a blue-shift in emission peaks of the $\mathrm{ZnO}$ 125 microrods.On the other hand, the lifetime shortening, which is characteristic in ASE and 
stimulated emission, is attributed to the nonradiative relaxation process. The picosecond lifetimes of the microrods, which are faster than bulk single crystals, are largely attributed to the effective nonradiative recombination with the activation of nonradiative recombination centers at room temperature $[\mathbf{2 1}, \mathbf{2 9}, \mathbf{3 1}, \mathbf{4 9}]$. With increasing excitation energy densities, nonradiative relaxation dominates the decay of the excited carrier population which in turn affects the radiative excitonic recombination [13].

For the microrods' optical emission, only ASE is observed since thedetected emissionis assumed to be anaverage over an ensemble of randomly-oriented microstructures. The microrod density (11 microrods per $100 \mu \mathrm{m}^{2}$ ) may be insufficient to induce random lasing.Additional investigations at low temperatures, with a wider range of energy densities and with a higher resolution spectrometer, are necessary to obtain more information on thecharacteristic blue-shifting and lifetime shortening of the amplified emissions of the $\mathrm{ZnO}$ microrods. A spectroscopic characterization of asingle microrod is also neededto analyze the optical confinement and exciton-photon interaction in the microstructure. Nevertheless, the

140 present results indicate thatthe $\mathrm{ZnO}$ microrods grown by the ACG method may be utilized to develop new UV-based optoelectronic devices.

\section{Conclusion}

We reported the room-temperature UV ASEof $\mathrm{ZnO}$ microrods fabricated by the ACG 145 method. The as-prepared $\mathrm{ZnO}$ microrods exhibited uniform and well-faceted structures with single UV near-band-edge emission. As the optical excitationenergy density increased, the emission intensity increased while the spectral linewidth decreased. The ASE was due to the strong optical confinement favored by the structural and optical quality of the $\mathrm{ZnO}$ microstructures. By TRPL spectroscopy, the ASE had shown to be characterized by 150 blue-shifted peaks and shortened picosecond lifetimes. These observations were attributed to 
the band filling and screening effects and to the nonradiative relaxation process. The results yielded possible important insights on the use of these microstructures for their potential short wavelength optoelectronic applications.

\section{Acknowledgement}

This work was supported by the Japan Science and Technology Agency (JST) through the Adaptable \& Seamless Technology Transfer Program through Target-driven R\&D (A-STEP) Grant Number AS241047M. 
Fig. 1: Typical SEM image of $\mathrm{ZnO}$ microrods prepared by ACG method.

Fig. 2: Room-temperature wide scan PL spectrum of $\mathrm{ZnO}$ microrods prepared by ACG 165 method.

Fig. 3: Streak camera images of the room-temperature UV emission of $\mathrm{ZnO}$ microrods prepared by ACG method for (a) 100, (b) 210 , and (c) $410 \mu \mathrm{J} / \mathrm{cm}^{2}$ excitation energy densities.

170 Fig. 4: Integrated (a) spectral and (b) temporal profiles of the room-temperature UV emission of $\mathrm{ZnO}$ microrods prepared by ACG method at different excitation energy densities. The fitted biexponential decay functions for the temporal profiles at 100,210 , and $410 \mu \mathrm{J} / \mathrm{cm}^{2}$ are $0.63 \exp (-t / 70 \mathrm{ps})+0.38 \exp (-t / 130 \mathrm{ps}), 0.68 \exp (-t / 40 \mathrm{ps})+0.40 \exp (-t / 120 \mathrm{ps})$, and $0.87 \exp (-t / 30 \mathrm{ps})+0.26 \exp (-t / 140 \mathrm{ps})$, respectively.

Fig. 5: L-L curve of $\mathrm{ZnO}$ microrods prepared by ACG method.

Fig. 6: Room-temperature UV emission (a) peak centers and (b) average lifetimes of $\mathrm{ZnO}$ microrods prepared by ACG method at different excitation energy densities.

Fig. 7: Structure of a $\mathrm{ZnO}$ microrod prepared by ACG method: (a) SEM image of a single microrod; (b) hexagonal wurtzite crystal structure of $\mathrm{ZnO}$ (The dark and light spheres represent the zinc $\left(\mathrm{Zn}^{2+}\right)$ and oxygen $\left(\mathrm{O}^{2-}\right)$ ions, respectively); (c) typical crystal habit and growth of a microrod; and, (d) schematic representation of the optical confinement of the UV 185 emission (represented by the blue arrows) inside a microrod. 


\section{References}

[1] R.F. Service, "Will UV Lasers Beat the Blues?," Science276(5314) (1997) 895.

[2] Ü. Özgur, Y.I. Alivov, C. Liu, A. Teke, M.A. Reshikov, S. Doğan, V. Avrutin, S.-J. Cho, H. Morkoç, "A comprehensive review of $\mathrm{ZnO}$ materials and devices," J. Appl. Phys.98(2005) 041301.

[3] A.B. Santos-Putungan, L.M. Bambao, R.V. Sarmago, "Electrical properties of an individual ZnO micro/nanorod," Int. J. Philipp. Sci. Technol.1(1) (2015) 43-45.

[4] L. Zhang, J. Zhao, J. Zheng, L. Li, Z. Zhu, "Shuttle-like ZnO nano/microrods: facile synthesis, optical characterization and high formaldehyde sensing properties," Appl. Surf. Sci.258(2) (2011) 711-718.

[5] S. López-Romero, M. García-H, "Photoluminescence and structural properties of $\mathrm{ZnO}$ nanorods growth by assisted-hydrothermal method," World J. Condens. Mat. Phys.3(3) (2013) 152-157.

[6] Z. Huang, C. Chai, B. Cao, "Temperature-dependent emission shifts of peanutlike ZnO microrods synthesized by a hydrothermal method," Cryst. Growth Des.7 (9) (2007) 1686-1689.

[7] Z.H. Ibupoto, K. Khun, M. Eriksson, M. AlSalhi, M. Atif, A. Ansari, M. Willander, "Hydrothermal growth of vertically aligned $\mathrm{ZnO}$ nanorods using a biocomposite seed layer of ZnO nanoparticles," Materials6(8) (2013) 3584-3597.

[8] C.X. Xu, A. Wei, X.W. Sun, Z.L. Dong, "Aligned ZnO nanorods synthesized by a simple hydrothermal method," J. Phys. DAppl. Phys.39(8) (2006) 1690-1693.

[9] W.M. Kwok, A.B. Djurišić, Y.H. Leung, D. Li, K.H. Tam, D.L. Phillips, W.K. Chan, "Influence of annealing on stimulated emission in $\mathrm{ZnO}$ nanorods," Appl. Phys. Lett.89 (2006) 183112.

[10] W. Li, Y. Sun, J. Xu, "Controllable hydrothermal synthesis and properties of ZnO hierarchical micro/nanostructures," Nano Micro Lett.4 (2) (2012) 98-102.

[11] G. Nagaraju, S. Ashoka, P. Chithaiah, C.N. Tharamani, G.T. Chandrappa, "Surfactant free hydrothermally derived $\mathrm{ZnO}$ nanowires, nanorods, microrods and their characterization," Mat. Sci. Semicon. Proc.13(1) (2010) 21-28.

[12] H. Zhang, D. Yang, X. Ma, Y. Ji, J. Xu, D. Que, "Synthesis of flower-like ZnO nanostructures by an organic-free hydrothermal process," Nanotechnology 15 (2004) 622-626.

[13] C.P. Li, L. Guo, Z.Y. Wu, L.R. Ren, X.C. Ai, J.P. Zhang, Y.Z. Lv, H.B. Xu, D.P. Yu, "Photoluminescence and time-resolved photoluminescence of star-shaped $\mathrm{ZnO}$ nanostructures," Solid State Comm.139 (2006) 335-359.

[14] F. Wen, W. Li, J.-H. Moon, J.H. Kim, "Hydrothermal synthesis of ZnO:Zn with green emission at low temperature with reduction process," Solid State Comm.135(1-2) 
(2005) 34-37.

[15] P.M. Aneesh, K.A. Vanaja, M.K. Jayaraj, "Synthesis of $\mathrm{ZnO}$ nanoparticles by hydrothermal method," Proc. SPIE6639 (2007) 66390J.

[16] A.B. Santos-Putungan, B.G. Singidas, R.V. Sarmago, "Manipulation of low temperature grown $\mathrm{ZnO}$ rigid structures via atomic force microscope," HCTL Open Int. J. Technol. Innov. Res. 11 (2014) 1-8.

[17] M.H. Huang, S. Mao, H. Feick, H. Yan, Y. Wu, H. Kind, E. Weber, R. Russo, P. Yang, "Room temperature ultraviolet nanowire lasers," Science292(5523) (2001) 1897-1899.

[18] P. Zu, Z.K. Tang, G.K.L. Wong, M. Kawasaki, A. Ohtomo, H. Koinuma, Y. Segawa, "Ultraviolet spontaneous and stimulated emissions from $\mathrm{ZnO}$ micro crystallite thin films at room temperature," Solid State Comm.103 (1997) 459-463.

[19] D.M. Bagnall, Y.F. Chen, Z. Zhu, T. Yao, M.Y. Shen, T. Goto, "High temperature excitonic stimulated emission from ZnO epitaxial layers," Appl. Phys. Lett.73 (1998) 1038-1040.

[20] H. Cao, J.Y. Xu, D.Z. Zhang, S.-H. Chang, S.T. Ho, E.W. Seelig, X. Liu, R.P.H. Chang, "Spatial confinement of laser light in active random media," Phys. Rev. Lett.84(24) (2000) 5584-5587.

[21] Ü. Özgür, A. Teke, C. Liu, S.-J. Cho, H. Morkoç, "Stimulated emission and time-resolved photoluminescence in rf-sputtered $\mathrm{ZnO}$ thin films," Appl. Phys. Lett.84(17) (2004) 3223.

[22] J.C. Johnson, H. Yan, P. Yang, R.J. Saykally, "Optical cavity effects in ZnO nanowire lasers and waveguides,” J. Phys. Chem. B107(34) (2003) 8816-8828.

[23] S.F. Yu, C. Yuen, S.P. Lau, W.I. Park, G.-C. Yi, "Random laser action in ZnO nanorod arrays embedded in ZnO epilayers," Appl. Phys. Lett.84(17) (2004) 3241-3243.

[24] Y.H. Leung, W.M. Kwok, A.B. Djurišić, D.L. Phillips, W.K. Chan, "Time-resolved study of stimulated emission in ZnO tetrapod nanowires," Nanotechnology16 (2005) 579-582.

[25] H. Morkoç and Ü. Özgür, Zinc Oxide: Fundamentals, Materials and Device Technology, Ch. 3: Optical Properties, Wiley-VCH Verlag GmbH \& Co. KGaA, Weinheim, 2009.

[26] T. Voss, C. Bekeny, L. Wischmeier, H. Gafsi, S. Börner, W. Schade, A.C. Mofor, A. Bakin. A. Waag, "Influence of exciton-phonon coupling on the energy position of the near-band-edge photoluminescence of ZnO nanowires," Appl. Phys. Lett.89 (2006) 182107.

[27] Y.C. Kong, D.P. Yu, B. Zhang, W. Fang, S.Q. Feng, "Ultraviolet-emitting ZnO nanowires synthesized by a physical vapor deposition approach," Appl. Phys. Lett.78 (4) (2001) 407-409.

[28] Y.J. Xing, Z.H. Xi, Z.Q. Que, X.D. Zhang, J.H. Song, R.M. Wang, J. Xu, S.L. Zhang, D.P. Yu, "Optical properties of the $\mathrm{ZnO}$ nanotubes synthesized via vapor phase growth," 
Appl. Phys. Lett.83 (9) (2003) 1689-1891.

[29] M.J.F. Empizo, K. Fukuda, R. Arita, Y. Minami, K. Yamanoi, T. Shimizu, N. Sarukura, R.M. Vargas, A.A. Salvador, R.V. Sarmago, "Photoluminescence properties of a single $\mathrm{ZnO}$ microstructure for potential scintillator applications," Opt. Mater.38 (2014) 256-260.

[30] I. Shalish, H. Temkin, V. Narayanamurti, "Size-dependent surface luminescence in $\mathrm{ZnO}$ nanowires,"Phys. Rev. B69 (2004) 245401.

[31] W.M. Kwok, A.B. Djurišić, Y.H. Leung, W.K. Chan, D.L. Phillips, "Time-resolved photoluminescence from ZnO nanostructures,"Appl. Phys. Lett.87(2005) 223111.

[32] D. Wang, J. Yang, G. Xiang, L. Yang, J. Lang, M. Gao, B. Yao, T. Wu, “Abnormal blueshift of UV emission in single crystalline ZnO nanowires,"J. Lumin.129(9) (2009) 996-999.

[33] B. Zou, R. Liu, F. Wang, A. Pan, L. Cao, Z.L. Wang, "Lasing mechanism of ZnO nanowires/nanobelts at room temperature,"J. Phys. Chem. B110(26) (2006) 12865-12873.

[34] J.R. Lakowicz, Principles of Fluorescence Spectroscopy, $3^{\text {rd }}$ ed, Ch. 4: Time-Domain Lifetime Measurements, Springer Science+Business Media, LLC, Singapore, 2006.

[35] G.P. Zhu, C.X. Xu, J. Zhu, X. Li, K. Zheng, J.P. Liu, C.G. Lu, Y.P. Cui, "Characteristics of ultraviolet amplified spontaneous emission from zinc oxide nanowires,"Opt. Mater.31(2) (2008) 181-183.

[36] M.A. Zimmler, J. Bao, F. Capasso, S. Müller, C. Ronning, "Laser action in nanowires: observation of the transition from amplified spontaneous emission to laser oscillation,"Appl. Phys. Lett.93(2008) 051101.

[37] M. Ding, D. Zhao, B. Yao, E. Shulin, Z. Guo, L. Zhang, D. Shen, “The ultraviolet laser from individual $\mathrm{ZnO}$ microwire with quadrate cross section," Opt. Express 20(13) (2012) 13657-13662.

[38] C.X. Xu, X.W. Sun, C. Yuen, B.J. Chen, S.F. Yu,Z.L. Dong, "Ultraviolet amplified spontaneous emission from self-organized network of zinc oxide nanofibers," Appl. Phys. Lett.86(2005) 011118.

[39] S.F. Yu, C. Yuen, S.P. Lau, Y.G. Wang, H.W. Lee, B.K. Tay, "Ultraviolet amplified spontaneous emission from zinc oxide ridge waveguides on silicon substrate,"Appl. Phys. Lett.83(21) (2003) 4288-4290.

[40] H. Cao, J. Y. Xu, S.-H. Chang, and S.T. Ho, "Transition from amplified spontaneous emission to laser action in strongly scattering media," Phys. Rev. E61(2) (2000) 1985-1989.

[41] Y. Zhong, Z. Yue, G.K.L. Wong, Y.Y. Xi, Y.F. Hsu, A.B. Djurišić, J.-W. Dong, W.-J. Chen, K.S. Wong, "Enhancement of spontaneous emission rate and reduction in amplified spontaneous emission threshold in electrodeposited three-dimensional $\mathrm{ZnO}$ 
photonic crystal," Appl. Phys. Lett.97(2010) 191102.

[42] Y.T. Shih, M.K. Wu, W.C. Li, H. Kuan, J.R. Yang, M. Shiojiri, M.J. Chen, “Amplified spontaneous emission from $\mathrm{ZnO}$ in $\mathrm{n}-\mathrm{ZnO} / \mathrm{ZnO}$ nanodots-SiO ${ }_{2}$ composite/p-AlGaN heterojunction light-emitting diodes," Nanotechnology20(16) (2009) 165201.

[43] P. Yang, G. Wirnsberger, H.C. Huang, S.R. Cordero, M.D. McGehee, B. Scott, T. Deng, G.M. Whitesides, B.F. Chmelka, S.K. Buratto, G.D. Studky, "Mirrorless lasing from mesostructured waveguides patterned by soft lithography," Science287(5452) (2000) 465-467.

[44] L. Vayssieres, "Growth of arrayed nanorods and nanowires of $\mathrm{ZnO}$ from aqueous solutions," Adv. Mater. 15 (5) (2003) 464-466.

[45] R.A. Laudise, A.A. Ballman, "Hydrothermal synthesis of zinc oxide and zinc sulfide," J. Phys. Chem.64 (5) (1960) 688-691.

[46] D. Polsongkram, P. Chamninok, S. Pukird, L. Chow, O. Lupan, G. Chai, H. Khallaf, S. Park, A. Schulte, "Effect of synthesis conditions on the growth of $\mathrm{ZnO}$ nanorods via hydrothermal method," Physica B 403 (2008) 3713-3717.

[47] S. Chen, Y. Liu, C. Shao, R. Mu, Y. Lu, J. Zhang, D. Shen, X. Fan, "Structural and optical properties of uniform $\mathrm{ZnO}$ nanosheets," Adv. Mater.17 (2005) 586-590.

[48] X.W. Sun, H.S. Kwok, "Optical properties of epitaxially grown zinc oxide films on sapphire by pulsed laser deposition," J. Appl. Phys.86(1) (1999) 408-411.

[49] T. Koida, S.F. Chichibu, A. Uedono, A. Tsukazaki, M. Kawasaki, T. Sota, Y. Segawa, H. Koinuma, "Correlation between the photoluminescence lifetime and defect density in bulk and epitaxial ZnO,” Appl. Phys. Lett.82 (4) (2003) 532-534. 


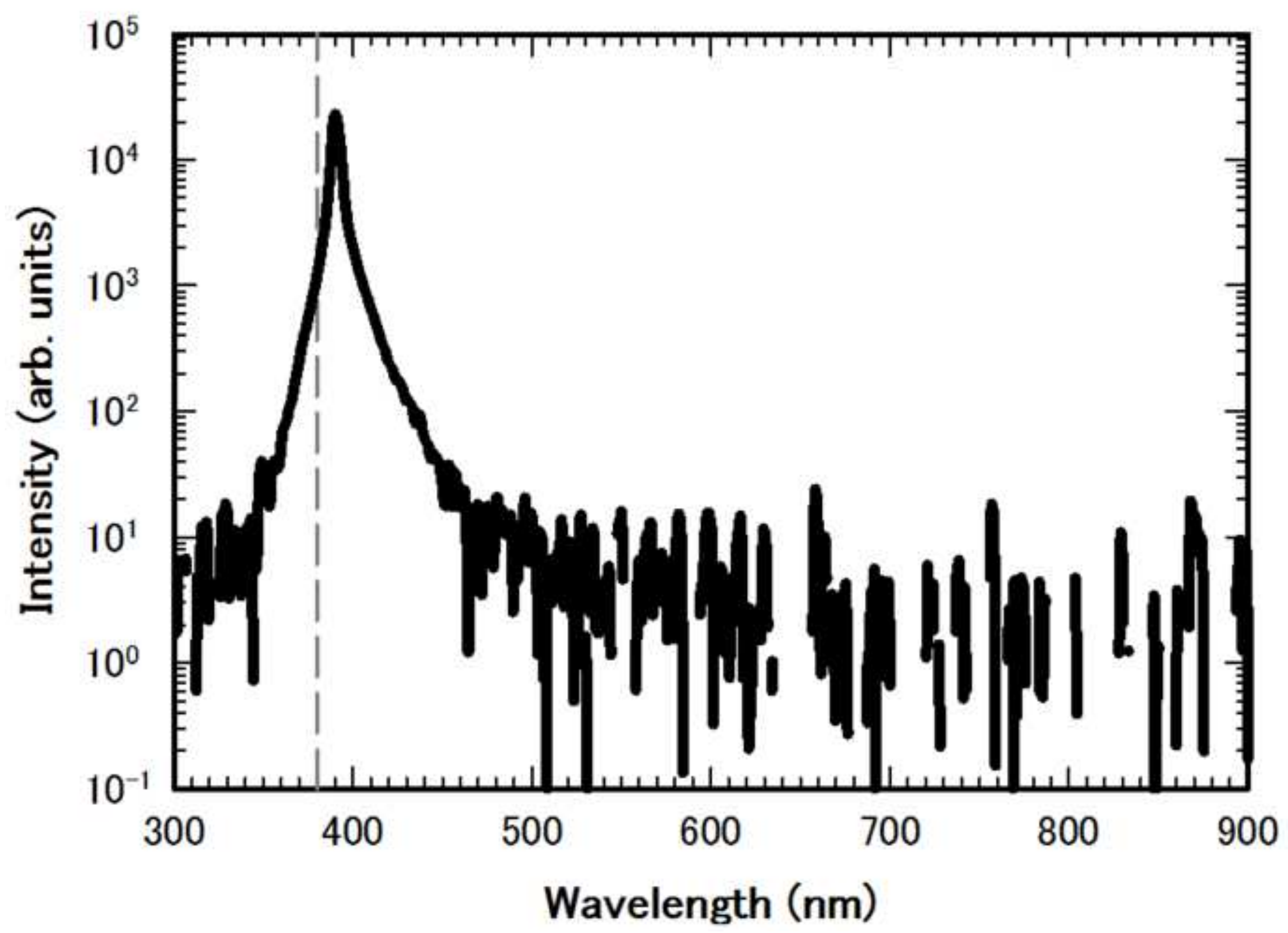



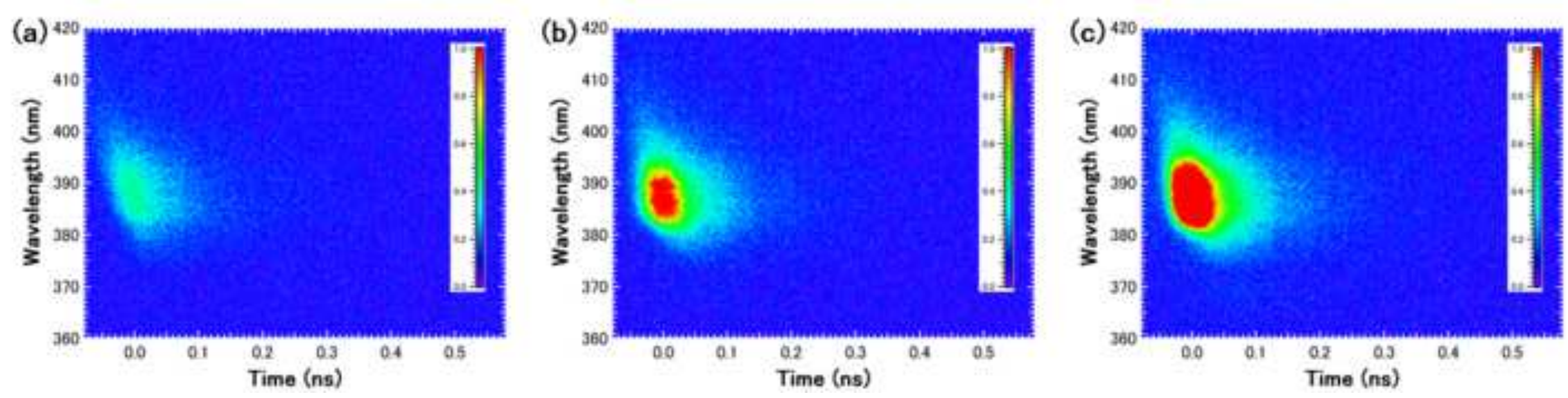

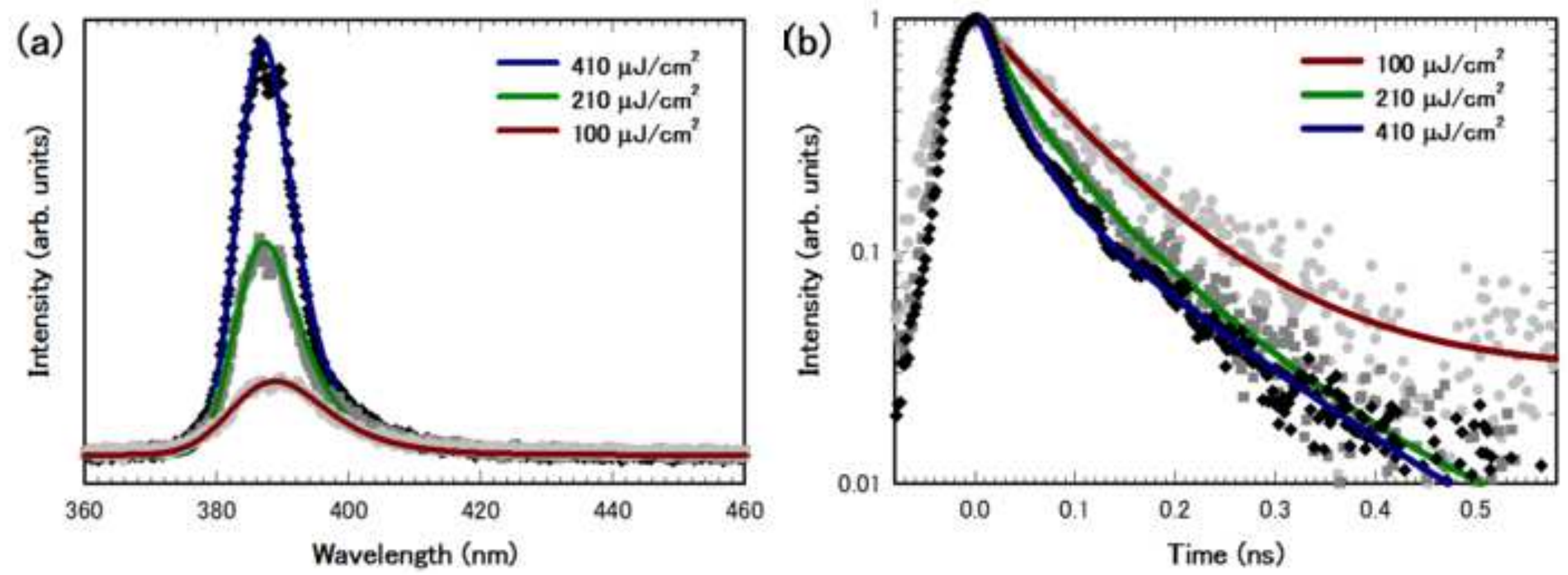


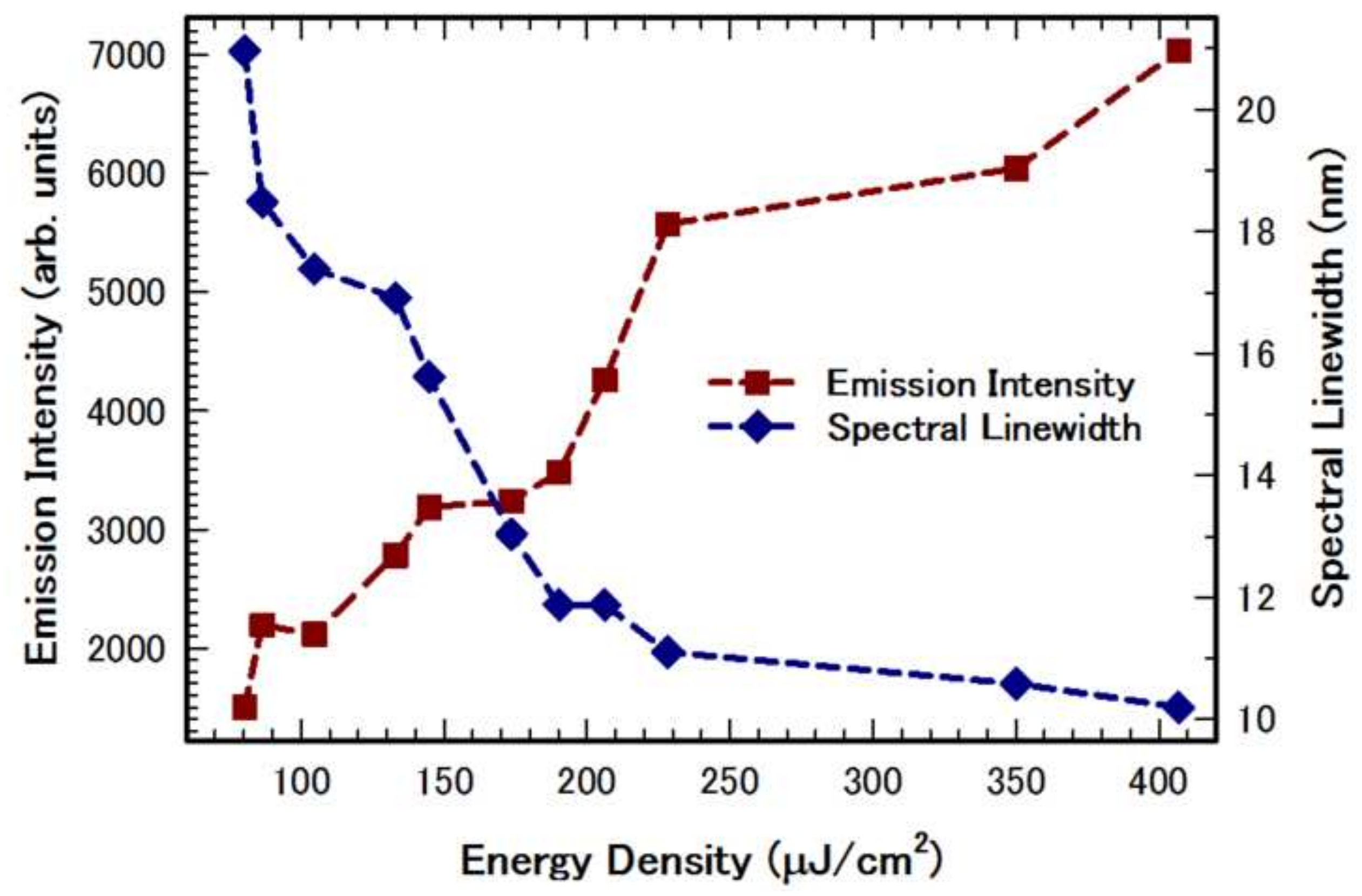



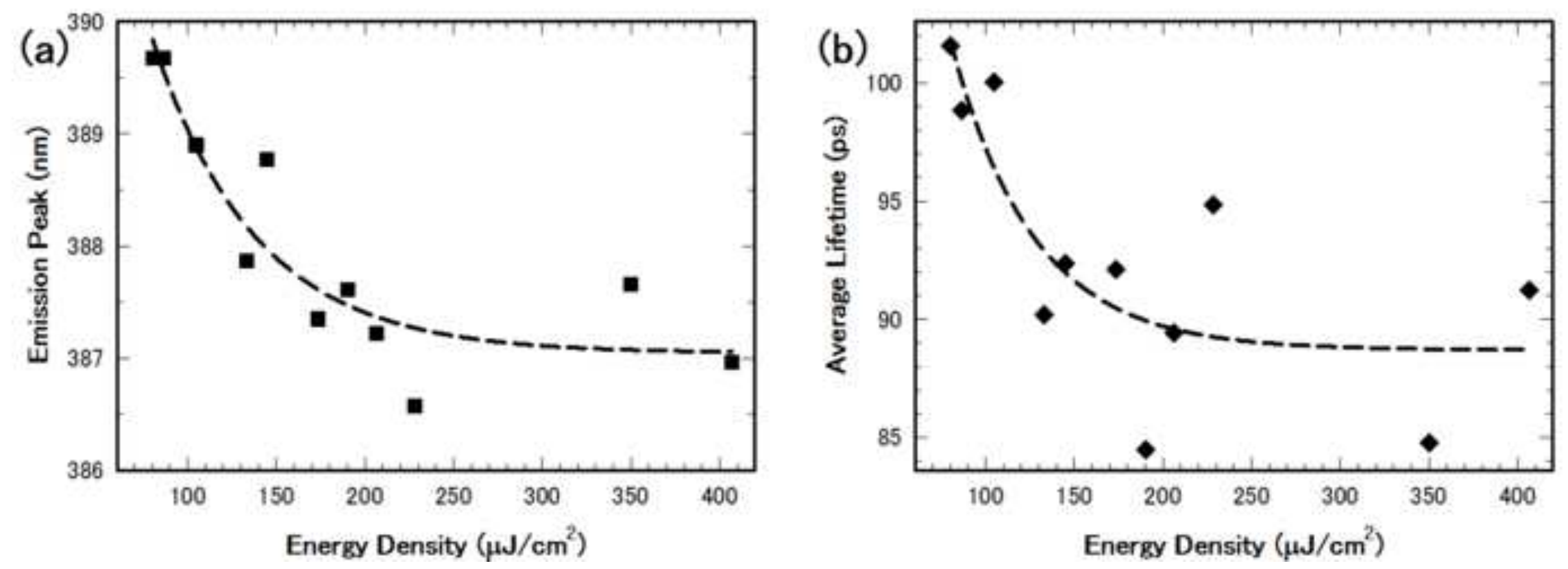


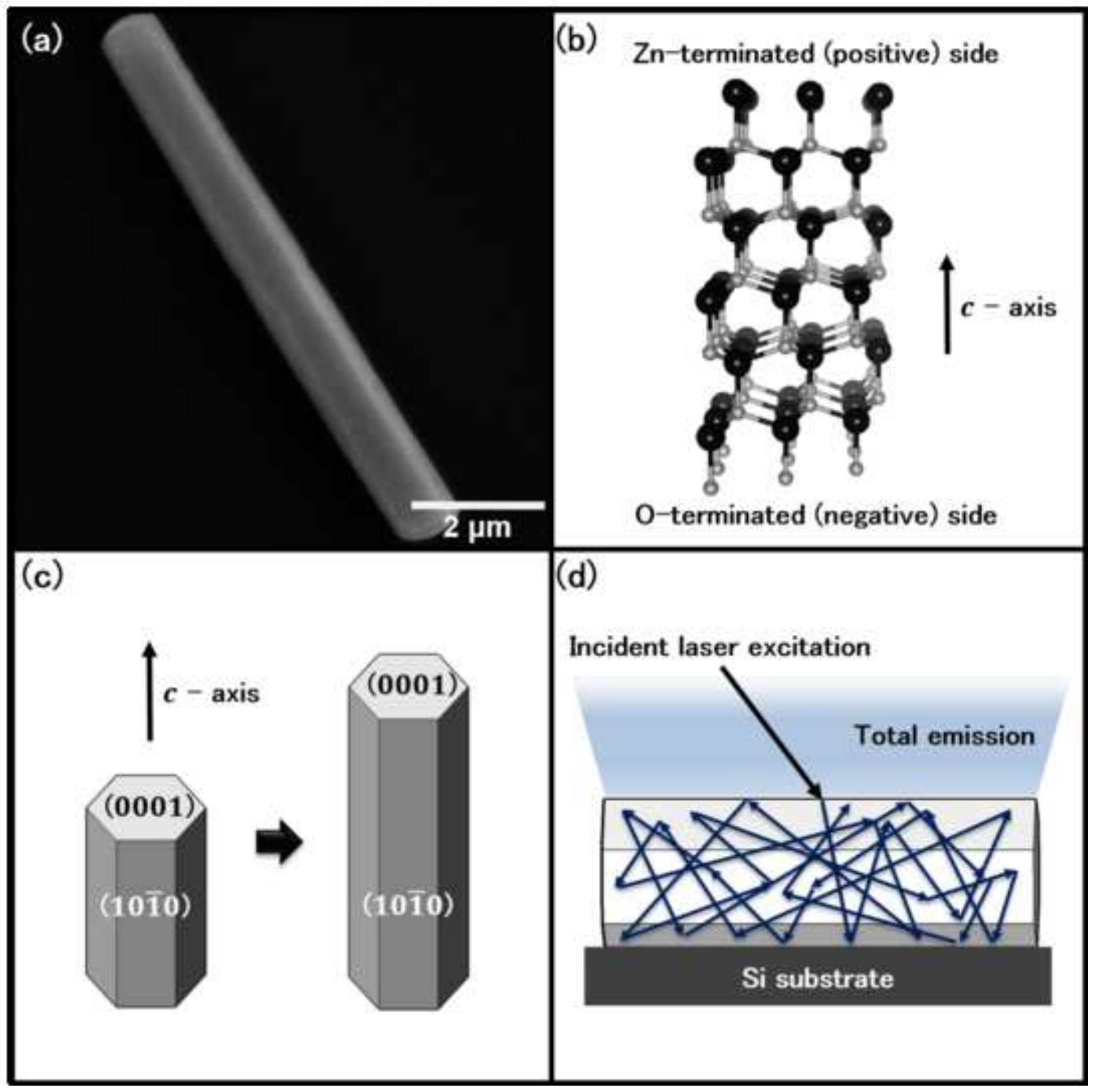

